\title{
Imaging Mass Spectrogram using Rotating Electric Fields Mass Spectrometer
}

\author{
Masashi Nojima* \\ Tokyo University of Science, Japan
}

Submission: July 27, 2017; Published: August 04, 2017

*Corresponding author: Masashi Nojima, Associate Professor, Tokyo University of Science, Japan, Tel: +81-4-7124-1501;

E-mail:mnojima@rs.noda.tus.ac.jp

\begin{abstract}
We have been developing double rotating electric fields (REFs) type mass spectrometer, which can draw imaging mass spectrogram. On imaging mass spectrogram, different masses draw annular ring patterns with respect to their existences and intensities on the same field of in the same time. The specific mass draws a full cycloidal trajectory from the center axis of beam to the outside just in one cycle of first REF, then draws a mirror trajectory returning back to the axis within the other cycle of second REF and finally converge to the spot on center axis. The other masses draw different and partial cycloidal trajectories and assume different radius annular patterns after all isotonic movements or spin off from REFs.

In this study, AuGe alloy was selected as a source of imaging mass spectrometry. On a specific frequency of REFs, ${ }^{197} \mathrm{Au}^{+}$mass was converged to the center and the other masses formed concentric annular rings with different diameters from the center. On the other frequency, ${ }^{197} \mathrm{Au}^{2+}$ mass was converged to the center and Ge isotopes formed annular rings in concentric order. We have separated different masses or isotopes of AuGe alloy on different imaging mass spectrograms changing specific frequencies. This unique technique is disable for rapid imaging mass spectrometry by SIMS and MALDI technique or industrial mass implantation processes.
\end{abstract}

Keywords: Double rotating electric fields; Imaging mass spectrogram

Abbreviations: SIMS: Secondary Ion Mass Spectrometry; MALDI: Matrix-Assisted Laser Desorption Ionization; REF: Rotating Electric Field; FIB:Focused Ion Beam; MCP:Micro Channel Plate; DDS: Direct Digital Synthesizer

\section{Introduction}

Imaging mass spectrometric technologies are innovating biological or medical scientific reorganizations using secondary ion mass spectrometry (SIMS) or matrix-assisted laser desorption ionization (MALDI) imaging [1]. This article briefly introduces" an imaging mass spectrogram" by new principle double rotating electric fields (REFs) type mass spectrometer $[2,3]$. The imaging mass spectrogram indicates not spatial mass distributions but mass constitutions. Different masses draw annular ring patterns with respect to their existences and intensities on the same field of in the same time. The imaging mass spectrogram can be obtained by specific features of REFs type mass spectrometer; separates mass weight by filtering in high speed double REFs and draws annular ring patterns with direct continuous beam, simultaneously. The imaging mass spectrograms are mostly controlled by frequencies and intensities of REFs. The relationship with a specific frequency: $f$ and a weight of single charged mass: $m$ can be described by following equation [4].

$$
f=\frac{1}{L} \sqrt{\frac{2 e V_{a c c}}{m}}
$$

Where, $L$ is the length of each REF electrode, $e$ is the quantum of electricity, and $V_{a c c}$ is the accelerating potential of the charged masses. The specific mass draws a full cycloidal trajectory the center axis of beam to the outside just in one cycle of first REF, then draws a mirror trajectory returning back to the axis within the other cycle of second REF and finally converge to the spot on center axis. The other masses draw different and partial cycloidal trajectories and assume different radius annular patterns after all as so tonic movements or spin off from REFs. In this article, we observed the mass spectrometric images of AuGe alloy on different specific frequencies.

\section{Conclusion}

We connected a mass spectrometer consisting of double REF units to a focused ion beam (FIB) column (FIB30, A\&D Company, Ltd.). The inner diameters and the lengths of each REF unit 
were 20 and $150 \mathrm{~mm}$, respectively. The distance between the first REF unit and the second REF unit was $70 \mathrm{~mm}$. An aperture unit with a Faraday cup and micro channel plates (MCPs) with fluorescent screen were movably located behind the REFs. The aperture unit is movable from the downstream of REFs. We can switch between the imaging mass spectrometry mode and the ion-beam current detection mode. We introduced direct digital synthesizers (DDSs) to generate the sinusoidal waves for the REFs. The DDSs generate the sinusoidal waves with 16 differentphase channels. Each output sinusoidal wave is amplified by each high-frequency, high-voltage power amplifier and applied to each electrode of the double REF unit. We selected AuGe alloy as a source of imaging mass spectrometry. The accelerating voltage of the AuGe-FIB was $10 \mathrm{kV}$. The alternative potential of each sinusoidal wave was $230 \mathrm{~V}$ (peak to peak).

First, we set the imaging mass spectrometry mode and optimized the phase contrast between the first REF and second REF to make the phases of each REF mutually opposite for the specific mass from AuGe alloy. The phase contrast was depended on the travel time of the specific mass between the first REF and the second REF. The selected masses converged to the center axis because of the optimized phase contrast. Then, we set the movable aperture unit and measured the ion-beam current. The annular patterns of AuGe alloy were obtained by sweeping the frequencies of the REFs from 290 to $1,120 \mathrm{kHz}$ in steps of $5 \mathrm{kHz}$.
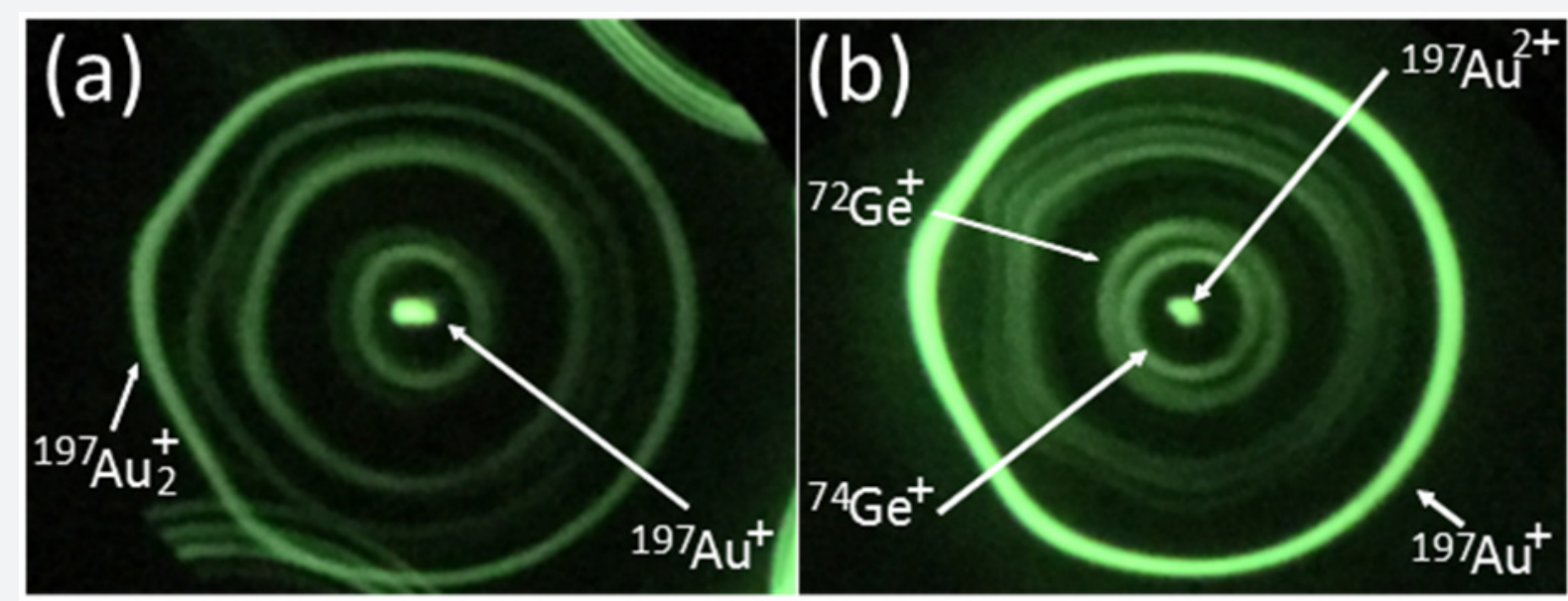

Figure a \& b: Imaging mass spectrograms of AuGe alloy by REFs spectrometer on each specific frequency.

(a) $f=675 \mathrm{kHz}, \mathrm{m} / \mathrm{Z}=197 \mathrm{AMU}$ (b) $\mathrm{f}=960 \mathrm{kHz}, \mathrm{m} / \mathrm{Z}=98.5 \mathrm{AMU}$.

Figure $\mathrm{a} \& \mathrm{~b}$ represent imaging mass spectrograms on different frequencies of the REFs. On Figure a, ${ }^{197} \mathrm{Au}^{+}$masswas converged to the center and the other masses formed concentric annular rings with different diameters from the center. On the other hand of Figure b, ${ }^{197} \mathrm{Au}^{2+}$ mass was converged to the center and $\mathrm{Ge}$ isotope masses formed annular rings in concentric order. There are also the other annular rings outside of Ge isotope rings, however the origins of annular rings on imaging mass spectrograms cannot be identified up to now. In principle, these annular rings are not always stood in order of each mass weight.

We separated different masses or isotopes of AuGe alloy on imaging mass spectrogram. This technique can be applied for rapid imaging mass spectrometry by SIMS and MALDI technique or mass industrial mass implantation processes.

\section{Acknowledgement}

The author is particularly indebted to Mr. Takashi Kusanagi of Ampere, Inc., Dr. Satoshi Kurumi, Prof. Kaoru Suzuki of Nihon
University and Prof. Kosuke Moritani of University of Hyogo. This unique technique was originally invented by Mr. Masanao Hotta and Dr. Tatsuya Adachi. I wish to express great respects for them.

\section{Conflict of Interest}

This work was supported in part by the JST Sentan Project (2013-2016).

\section{References}

1. McDonnell LA, Heeren RM (2007) Imaging mass spectrometry. Mass Spectrom Rev 26(4): 606-643.

2. Masashi N, Yuki A, Masanao H, Kaoru S, Satoshi K, et al. (2016) Development of a mass spectrometer using two rotating electric fields. J Vac Sci Technol B 34(3): 03H132-1-03H132-4.

3. Hotta M, Adachi T (2016) Japan patent 2016-507127.

4. Yuki A, Masashi N, Masanao H, Kaoru S, Takashi K, et al. (2016) Development of Mass Spectrometer Using Two Rotating Electric Fields for Separation of High-Mass Ions. e-J Surf Sci Nanotech 14: 161-164. 

(C) Coms work is licensed under Creative
DOI: 10.19080/GJN.2017.02.555596
Your next submission with JuniperPublishers will reach you the below assets

- Quality Editorial service

- Swift Peer Review

- Reprints availability

- E-prints Service

- Manuscript Podcast for convenient understanding

- Global attainment for your research

- Manuscript accessibility in different formats

( Pdf, E-pub, Full Text, Audio)

- Unceasing customer service

Track the below URL for one-step submission https://juniperpublishers.com/submit-manuscript.php 